\title{
Ectopic pregnancy: an observational study in a tertiary care centre of Southern Rajasthan, India
}

\author{
Shrusti Parmar, Nalini Sharma*, Vimla Dhakar \\ Department of Obstetrics and Gynecology, Geetanjali Medical College, Udaipur, Rajasthan, India
}

Received: 31 December 2019

Accepted: 07 January 2020

*Correspondence:

Dr. Nalini Sharma,

E-mail: udaipur14042015@gmail.com

Copyright: ( $\odot$ the author(s), publisher and licensee Medip Academy. This is an open-access article distributed under the terms of the Creative Commons Attribution Non-Commercial License, which permits unrestricted non-commercial use, distribution, and reproduction in any medium, provided the original work is properly cited.

\begin{abstract}
Background: One among the three chief obstetric causes of bleeding in first trimester, ectopic pregnancy is the first thing to rule out as a gestation is suspected. The present study observes and analyses sociodemographic distribution, risk factors, presentation, diagnosis and treatment modalities in a tertiary care centre.

Methods: An observational cross-sectional study, conducted among patients who were diagnosed and managed in department of obstetrics and gynaecology of a tertiary care centre. Data analyzed and explained as frequency, percentage, mean and standard deviation.

Results: Age group between 21 to 30 years $(69.9 \%)$ and multigravida (68.5\%) are high risk for ectopic pregnancy (EP). Menstrual history was regular in $86.3 \%$. Risk factors identified were previous abortion (30\%) and history of pelvic inflammatory disease (30\%). In $80.9 \%$ pain in abdomen was presenting complaints followed by bleeding per vaginum $(60 \%)$, amenorrhoea (60\%) and nausea and vomiting (32.9\%). Right salpingectomy was most common in $43.8 \%$, followed by left salpingectomy in $28.8 \%$, methotrexate in $15.1 \%$, left salpingo-ophorectomy in $5.5 \%$, right salpingo-opherectomy in 5.5\% and removal of tubal abortion in $1.3 \%$ patients. Laparoscopy was chosen route in majority $64.4 \%$ patients.

Conclusions: Ectopic pregnancy - a gynecological catastrophe as well as a major challenge to the reproductive performance of women worldwide, should be considered a relevant public health issue. By providing adequate materials, manpower, well-equipped health facilities as well as a prompt and efficient referral system, good access roads and efficient transportation, will ensure early presentation in hospitals and prompt management of cases.
\end{abstract}

Keywords: Blood transfusion, Ectopic pregnancy, Laparoscopy, Management, Risk factors

\section{INTRODUCTION}

Ectopic meaning other than the normal location when occurring in pregnancy, can be devastating. One among the three chief obstetric causes of bleeding in first trimester, is the first thing to rule out as soon as a gestation is confirmed. Catastrophic spectrum of ectopic pregnancy has been encountered by every obstetrician in her career, no matter the duration. Incidence varies worldwide between $0.25 \%$ to $2 \% .{ }^{1}$ Ectopic pregnancy still accounts for $3.5-7.1 \%$ of maternal deaths in India. ${ }^{2}$
Cultural norms, irregular lifestyle, variable presentations are few pieces of the puzzle.

As assisted reproduction incidences have raised, number of ectopic pregnancies has increased proportionately. With the advancements in imaging techniques, mortality has reduced over time as well as medical management has also become possible.

The present study observes and analyses sociodemographic distribution, risk factors, presentation, diagnosis, treatment modalities in a tertiary care centre. 


\section{METHODS}

This observational cross-sectional study was conducted among patients in department of obstetrics and gynaecology of Geetanjali Medical College and Hospital, Udaipur who were diagnosed with ectopic pregnancy and managed at hospital.

From January 2018 to December 2018, total sample size was not calculated and 73 patients were enrolled conveniently in study during the study period after their written informed consent.

\section{Inclusion criteria}

- All the patients of ectopic pregnancy admitted in $\mathrm{GMCH}$

- A pregnancy is called ectopic pregnancy when a fertilized ovum is implanted and develops outside the normal endometrial cavity

- All patients of age $>18$ years

- Patient who have signed written consent.

\section{Exclusion criteria}

- Patients who are not diagnosed with ectopic pregnancy following surgical intervention

- Patients' clinical presentation not consistent with sonographic findings.

Semi structured questionnaire, physical examination, laboratory investigation and radiological examination.

Enrolment of study participants and method of data collection.

Data collected on the basis of detailed history and clinical evaluation was done on all diagnosed ectopic pregnancy patients.

Detail history of the patient included: patient identity; complaints like history of amenorrhoea, acute pain abdomen, vaginal bleeding (if present - duration and nature), any attacks of syncope or vomiting, urinary or rectal symptoms, fever or other symptoms like backache or shoulder pain; detail menstrual and obstetric history including history of infertility or previous ectopic pregnancy, if present; history of previous surgery dilatation and curettage, tubal surgeries tuboplasty, appendicectomy or any other abdominal surgery; history of pelvic inflammatory disease or tuberculosis and treatment received for it; family history of tuberculosis; method of contraception - IUCD, oral contraceptive pill or permanent method

Clinical evaluation included general examination of patient - including presence of anaemia, shock, restlessness, cold and clammy extremities, pulse, respiration, blood pressure, temperature and cardiovascular and respiratory systems examinations; abdominal examination- for presence of mass, signs of free fluid in peritoneal cavity, guarding, rigidity, tenderness and presence of rare signs like Cullen's sign; vaginal examination for presence of bleeding, its nature, colour of the vaginal mucosa, position of the cervix, tenderness on movement of the cervix, size of the uterus, mobility and consistency, presence of mass and/or tenderness in any of the fornices; per-rectal examination whenever necessary for confirmation of findings.

On admission after a detailed examination, a sample of blood was drawn for blood grouping, Rh typing and cross-matching to arrange blood for transfusion. Investigations like $\mathrm{Hb} \%$, hematocrit, routine blood tests as advised by anaesthesiologists; total leukocyte count, differential count, ESR if necessary; urine pregnancy test and ultrasonography (USG) were carried out. In acute cases with the typical symptoms i.e. amenorrhoea, pain and bleeding which was confirmed by USG (wherever possible) followed by laparotomy/laparoscopy.

\section{Management of all diagnosed cases of ectopic pregnancy}

Patients in shock were managed and taken for surgery. Basic investigations were done, along with viral markers. Blood transfusion was given intra-operative or postoperative as per the requirement of individual cases.

Prophylactic antibiotics were given to all patients at the time of induction of anaesthesia. Early ambulation (within 6 hours of surgery) was ensured as is the protocol in our institute. Patients were followed up in the postoperative period with special attention to the development of fever, abdominal pain, distension of the abdomen and wound sepsis. Patients were discharged with an advice to come for follow up after a week.

Surgery was performed under either spinal or general anaesthesia. Route chosen was either minimally invasive or open surgery. When patient was hemodynamically unstable or gross collection in peritoneal cavity was reported in ultrasonography, open surgical approach was chosen. Abdomen was opened with suitable incision. The site of ectopic gestation, status of the fallopian tube, contralateral tube, ovaries and uterus was noted. As majority of the patients had ruptured tubal gestation, a decision for removal of the tube i.e., salpingectomy was made. Drain was put whenever gross hemoperitoneum due to ruptured ectopic gestation was present, in turn preventing effective peritoneal fluid removal. The removed tissue (tube or gestational sac) was sent for histopathological examination. Pathological reports are however not studied in this study.

Methotrexate was given for medical treatment after urine pregnancy positive by serial hormonal assay (beta hCG) and imaging (ultrasonography). 
Criterion for medical management - no intrauterine g-sac or fluid collection on transvaginal sonography, beta hCG level less than $2000 \mathrm{mIU} / \mathrm{ml}$, ectopic pregnancy less than $3.5 \mathrm{~cm}$, no fetal cardiac activity. Gastrointestinal, hepatic, renal and hemopoeitc disease was excluded. ${ }^{3}$

Relevant investigations (hematocrit, liver function tests etc.) were done before initiation of medical management.

Doses of methotrexate given- single dose intramuscular injection $\left(50 \mathrm{mg} / \mathrm{m}^{2}\right)$. Every 3 days beta hCG levels was repeated until negative. A fall of 15 percent between day 4 and 7 should occur, otherwise a second dose was given. With multidose methotrexate, levels are measured at 48 hours intervals until they fall more than $15 \%$. Once appropriately falling beta hCG levels are achieved in either regime, levels are then measured weekly until undetectable. Ultrasonographic assessment of reduction in the size of mass was done as and when required. Failure was judged if beta hCG levels plateaus or rises or tubal rupture occurs.

Follow up on outpatient basis, but if any issue of patient compliance, patient condition or safety of the treatment was present- hospitalization was offered.

\section{Ethical consideration}

Study was ethically approved by Institutional Research Review Committee and Institutional Ethical Committee. After ethical approval study was started and enrolled patients after their written informed consent. Confidentiality and privacy of the participants were maintained. All the data was kept in strict confidentiality with access to only the researcher and mentors

\section{Statistical analysis}

Data was entered in MS Excel 2010 spread sheet and analyzed with the help of Open Epi (freely available online), SPSS V.20 (freely available) and MS Excel (with licensed version).

- Qualitative data analyzed and explained as frequency and percentage

- Quantitative data analyzed and expressed as mean and SD

- Bar chart, pie chart and column diagram use for explained frequency and percentage.

\section{RESULTS}

Figure 1 shows most common age group was 26 years to 30 years $(38.4 \%)$ followed by 21 to 25 years $(31.5 \%)$, more than 30 years $(26 \%)$ and $4.1 \%$ (3) less than 20 years in our study.

Table 1 depicts nulliparous (31.5\%) women had maximum incidence followed by second para $(30.1 \%)$, primi para $(27.4 \%)$ and third para $(11 \%)$.
Ectopic pregnancy was found to be affecting more women with less than 5 years active married life $(52.1 \%)$, followed by 5 years to 10 years $(34.2 \%)$ and more than 10 years $(13.7 \%)$.

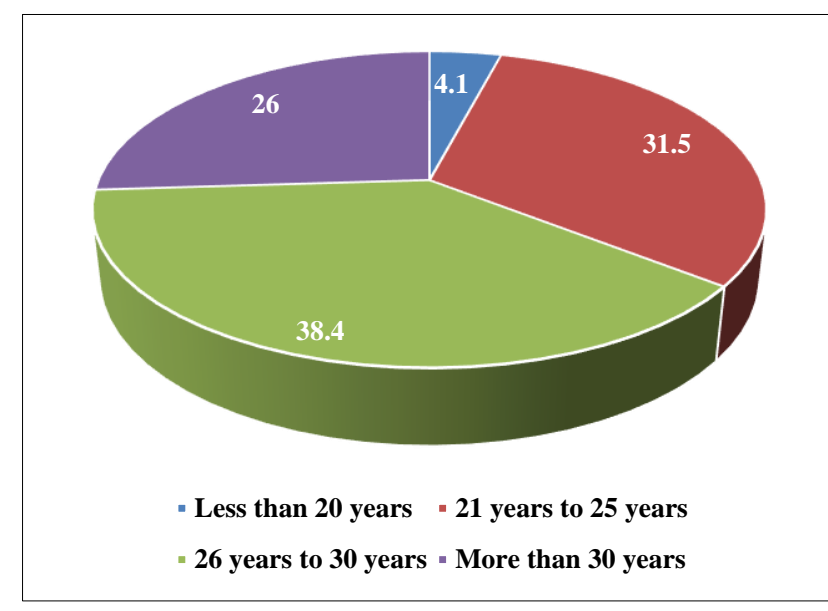

Figure 1: Distribution of ectopic pregnancy according age(n).

Table 1: Parity wise distribution of patients, distribution according to married life.

\begin{tabular}{|lll|}
\hline Parity & No. of patients & $\%$ \\
\hline Nulliparous & 23 & 31.5 \\
\hline Primi para & 20 & 27.4 \\
\hline Second para & 22 & 30.1 \\
\hline Third para & 8 & 11 \\
\hline Total & $\mathbf{7 3}$ & $\mathbf{1 0 0}$ \\
\hline Married life & \\
\hline Less than 5 years & 38 & 52.1 \\
\hline 5 years to 10 years & 25 & 34.2 \\
\hline More than 10 years & 10 & 13.7 \\
\hline Total & $\mathbf{7 3}$ & $\mathbf{1 0 0}$ \\
\hline
\end{tabular}
years.

Table 2: Previous menstrual history wise distribution, distribution of patients according to risk factors based on past history.

\begin{tabular}{|lll|}
\hline Menstrual history & No. of patients & $\%$ \\
\hline Regular & 63 & 86.3 \\
\hline Irregular & 10 & 13.7 \\
\hline Total & $\mathbf{7 3}$ & $\mathbf{1 0 0}$ \\
\hline Past history & & \\
\hline Previous abortion & 22 & 30.1 \\
\hline PID & 22 & 30.1 \\
\hline H/o infertility & 10 & 13.7 \\
\hline IUCD & 8 & 11 \\
\hline Tubal ligation & 6 & 8.3 \\
\hline H/o ectopic pregnancy & 1 & 1.4 \\
\hline Total & $\mathbf{7 3}$ & $\mathbf{1 0 0}$ \\
\hline
\end{tabular}

Table 2 describes that $86.3 \%$ patients reported regular menses followed by irregular menses in $13.7 \%$ patients. 
Most common risk factors identified were previous abortion $(30 \%)$ and pelvic inflammatory disease (30\%) based on past history. We also found history of infertility in $13.7 \%$ patients, use of IUCD in $11 \%$, tubal ligation in $8.3 \%$ and prior history of ectopic pregnancy in $1.4 \%$ patients. Although pelvic inflammatory condition is considered most common etilology of EP with reason being cilliary dysmotility, although the theory is currently being challenged.

Figure 2 shows pain in abdomen (80.9\%) was most common presenting symptom followed by bleeding per vaginum $(60 \%)$, amenorrhoea $(60 \%)$ and nausea and vomiting (32.9\%). That follows the triad of EP amenorrhea, bleeding per vaginum, pain abdomen.

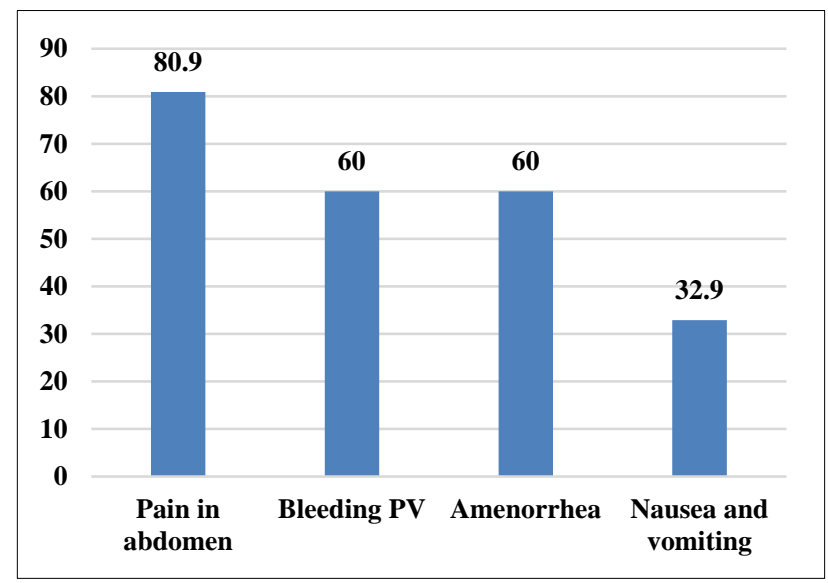

Figure 2: Distribution according to clinical features at the time of admission (\%).

Figure 3 shows most common general finding was abdominal tenderness in $45.2 \%$, pallor in $38.4 \%$, abdominal distension in $37 \%$, tachycardia in $27.4 \%$, guarding in $23.3 \%$ and raise temperature in $19.2 \%$ patients on general examination.

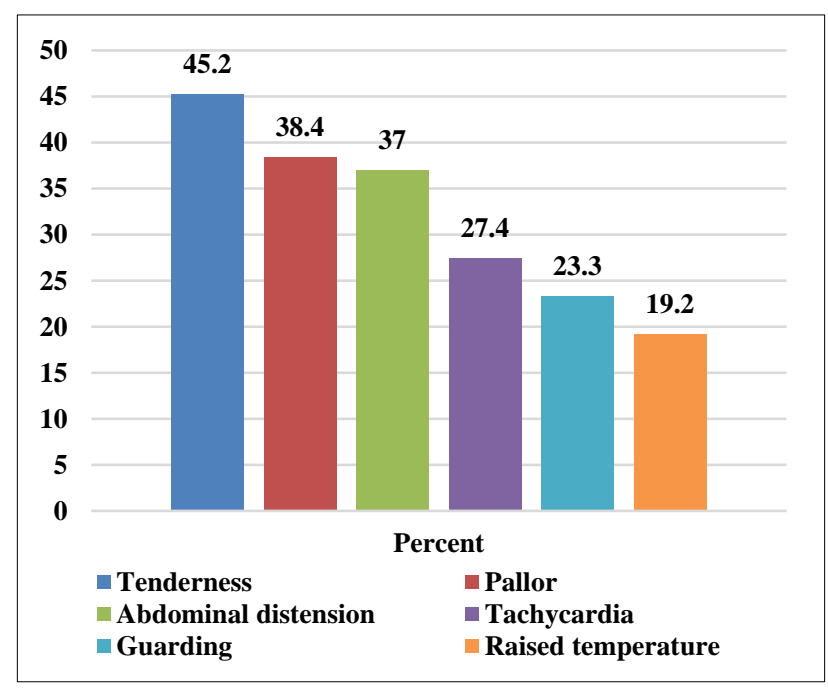

Figure 3: Distribution according to general examination $(\%)$.
Table 3 shows $65.6 \%$ (48/73) patients had retroverted and normal size uterus, bulky uterus was found in $17.8 \%$ females only. $93 \%$ had complaints of forniceal, tenderness, fullness in fornices in 22/73 (30.1\%).

Table 3: Distribution according to findings of uterus, forniceal finding.

\begin{tabular}{|lll|}
\hline Uterus position and size & No. of patients & $\%$ \\
\hline Bulky uterus & 13 & 17.8 \\
\hline Anteverted and normal size & 12 & 16.4 \\
\hline Retroverted and normal size & 48 & 65.6 \\
\hline Total & $\mathbf{7 3}$ & $\mathbf{1 0 0}$ \\
\hline Fornices & & \\
\hline Tenderness & 68 & 93.2 \\
\hline Fullness & 22 & 30.1 \\
\hline Mass & 17 & 23.3 \\
\hline
\end{tabular}

Figure 4 shows right sided ectopic $(58.9 \%)$ was found to be more common than left side $(41.1 \%)$.

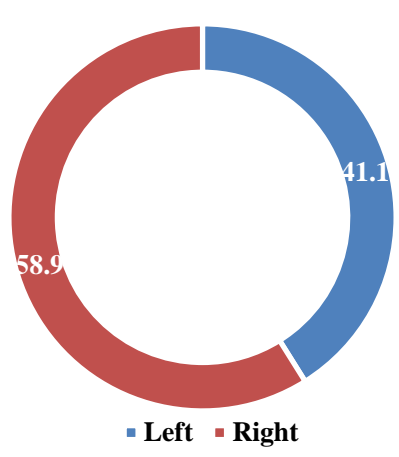

Figure 4: Tubal side involved wise distribution (\%).

Table 4: Distribution according to laboratory investigation, USG finding wise distribution.

\begin{tabular}{|lll|}
\hline Laboratory investigation & No. of patients & $\%$ \\
\hline UPT- Positive & 73 & 100 \\
\hline LFT-Normal & 73 & 100 \\
\hline \multirow{2}{*}{$\mathrm{Hb}(\mathrm{mg} / \mathrm{dl})$} & Mean & 9.9 \\
\cline { 2 - 3 } beta hCG & SD & 2.1 \\
\hline USG finding & Mean & 3886 \\
\hline Unruptured & SD & 3096.8 \\
\hline Ruptured & Number & $\mathbf{\%}$ \\
\hline Adnexal Mass & 42 & 57.53 \\
\hline Total & 28 & 38.35 \\
\hline USG finding acc. To side & 3 & 4.1 \\
\hline involved & $\mathbf{7 3}$ & $\mathbf{1 0 0}$ \\
\hline Adnexal mass & 1 & $\mathbf{R i g h t}$ \\
\hline Unruptured & 14 & 2 \\
\hline Ruptured & 14 & 28 \\
\hline Total & $\mathbf{3 0}$ & 14 \\
\hline & & $\mathbf{4 3}$ \\
\hline
\end{tabular}


Urine test was found positive in $100 \%$ of cases. Liver function tests are also found normal in $100 \%$ cases. Among all patients mean beta hCG was found 3886 micrograms/L as seen in Table 4.

Our study reported unruptured EP in $57.53 \%$ (42/73), followed by ruptured EP in $38.35 \%$ (28/73) and adnexal mass in $4.1 \%(3 / 73)$ patients.

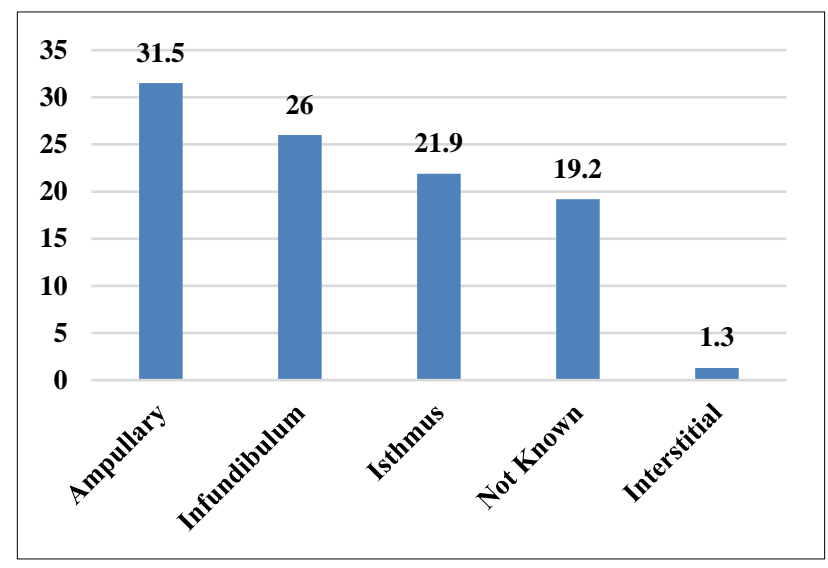

Figure 5: Site of ectopic pregnancy wise distribution (\%).

Table 4 shows side wise distribution of USG finding. On left side, ruptured EP in 14 patients, unruptured in 14 patients and adnexal mass in 1 patient. While on right side, unruptured EP in 28 patients, ruptured in 14 patients and adnexal mass in 2 patients.

Figure 5 shows most common site of EP was ampullary in $31.5 \%$ patients, followed by infundibulum in $26 \%$ patients, isthmus in $21.9 \%$ patients, tubal site not known in $19.2 \%$ patients and interstitial in $1.3 \%$ patients confirmed while surgery or ultrasonography. Site could not be known in 14 tubal ectopics as no mention was made in imaging report as well as surgical record of patient, when the investigator was not the part of surgical team.

Table 5 shows age wise distribution of site of ectopic pregnancy.

Ampulla - 11 in 26 to 30 years followed by 7 in 21 to 25 years of age group and 5 in more than 30 years of age group.

Infundibulum- 8 in 26 to 30 years followed by 6 in more than 30 years and 5 in 21 to 25 years of age group.

Isthmus- 6 in 26 to 30 years followed by 5 in more than 30 years of age, 3 in 21 to 25 years and 2 in less than 20 years of age.

Table 5: Age wise distribution with respect to tubal site involved.

\begin{tabular}{|c|c|c|c|c|c|}
\hline \multirow{2}{*}{ Site of ectopic } & \multicolumn{4}{|c|}{ Age } & \multirow[b]{2}{*}{ Total } \\
\hline & Less than 20 years & 21-25 years & 26-30 years & More than 30 years & \\
\hline Ampulla & 0 & 7 & 11 & 5 & 23 \\
\hline Infundibulum & 0 & 5 & 8 & 6 & 19 \\
\hline Interstitial & 0 & 0 & 0 & 1 & 1 \\
\hline Isthmus & 2 & 3 & 6 & 5 & 16 \\
\hline Tubal site Not known & 1 & 8 & 3 & 2 & 14 \\
\hline Total & 3 & 23 & 28 & 19 & 73 \\
\hline
\end{tabular}

Interstitial - one case in more than 30 years of age group.

Among patients in whom sites were not identified, 8 were in 221-25 years of age, 3 in 26 to 30 years of age, 2 in more than 30 years of age and 1 in less than 20 years of age.

Table 6 shows right salpingectomy was most common procedure in $43.8 \%$, followed by left salpingectomy in $28.8 \%$, methotrexate in $15.1 \%$, left salpingoophorectomy in $5.5 \%$, right salpingo-opherectomy in $5.5 \%$ and removal of tubal abortion in $1.3 \%$ patients.

In patients where methotrexate was given patient were managed on OPD basis. Necessary investigations were done and patient received the methotrexate injection and came for next injection. beta hCG was done before starting the therapy. And further management was done as said above.

It was a co-incidence that during study period all patients chosen for medical therapy responded well to it. None of the patients required conversion to surgical treatment in this group.

A total of 24 patients were received in varying degrees of shock. In 2 patients 4 units blood transfusion (BT) was given. Both patients were operated in emergency hours via laparotomy route and were the only ones requiring intensive care unit services. Ours being a tertiary care centre and in tribal area of Rajasthan, 32.9\% (24/73) patients received BT. 20 patients (13 opened by 
laparotomy +7 operated by laparoscopy) received 2 units of blood transfusion. Accessing the health services requires a considerable time in this tribal area that could explain the unstable hemodynamic condition that $32.9 \%$ patients arrived in.

Table 6: Distribution according to mode of treatment, blood transfusion, condition at the time of discharge.

\begin{tabular}{|lll|}
\hline Mode of treatment & No. of patients & $\%$ \\
\hline Rt Salpingectomy & 32 & 43.8 \\
\hline Lt Salpingectomy & 21 & 28.8 \\
\hline Methotrexate & 11 & 15.1 \\
\hline Lt salpingo-opherectomy & 4 & 5.5 \\
\hline Rt salpingo-opherectomy & 4 & 5.5 \\
\hline Tubal abortion removal & 1 & 1.3 \\
\hline Total & $\mathbf{7 3}$ & $\mathbf{1 0 0}$ \\
\hline Blood transfusion & & \\
\hline Yes & 24 & 32.9 \\
\hline Not needed & 49 & 67.1 \\
\hline Total & $\mathbf{7 3}$ & $\mathbf{1 0 0}$ \\
\hline Condition at discharge & & \\
\hline Normal & 73 & $100 \%$ \\
\hline Total & $\mathbf{7 3}$ & $\mathbf{1 0 0 \%}$ \\
\hline
\end{tabular}

As shown in Figure 6, laparoscopy was chosen route in $64.4 \%$ patients, laparotomy in $20.5 \%$ patients with no surgical intervention in $15.1 \%$ patients. $15.1 \%$ (11) patients were treated with medical management (methotrexate) alone.

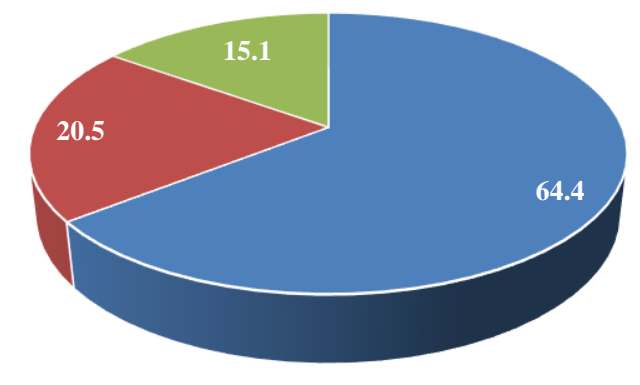

- Laparoscopy - Laparotomy $\quad$ No need of surgery

Figure 6: Mode of surgery wise distribution (\%).

\section{DISCUSSION}

Ectopic pregnancy is one of the life-threatening emergencies in pregnancy and a foremost cause of pregnancy death in the early days of pregnancy. In developing countries, ectopic pregnancy is still considered as cause for maternal morbidity and mortality. Because in these countries, majority of patients tend to present late with a ruptured form and hemodynamic compromise. ${ }^{4-6}$ During study period, we enrolled 73 patients who were diagnosed with ectopic pregnancy by one of the way and admitted in obstetrics and gynecology department, Geetanjali Hopsital, Udaipur, Rajsthan after their written informed consent.

\section{Incidence of ectopic pregnancy}

Study conducted by Rajendra Wakankar and Kshama Kedar in Nagpur in the year 2015 reported the incidence of ectopic pregnancy to be $1.99 \% .^{7}$ While study done by Shraddha Shetty K et al, reported the incidence of ectopic pregnancies was 5.6/1000 deliveries. ${ }^{8}$ Murugesan A et al, found the incidence of ectopic pregnancy $1.77 \% .{ }^{9}$ In a study by Costa et al, in 2004 the annual incidence of ectopic pregnancy worldwide was found to be $0.1-0.17$ in women of age group 15-44 years. ${ }^{10}$ Thus, overall incidence of ectopic pregnancy reported by various studies varied worldwide.

\section{Age group}

In present study most common age group reported in 26 years to 30 years $(38.4 \%)$ followed by 21 to 25 years $(31.5 \%)$, more than 30 years $(26 \%)$ and less than 20 years $(4.1 \%)$. We reported mean age in $28.2 \pm 4.9$ years with minimum 18 years and maximum 38 years. Study conducted by Rashmi et al, reported $70.2 \%$ cases belonged to the age group of 21-30 years. ${ }^{11}$ Panchal D et al the maximum incidence was seen in the age group of 21-30 years which was $71.66 \% .^{11}$ Study conducted by Dayal et al majority of cases belonged to age group of 25-29 years in $43.75 \% .{ }^{13}$ Study conducted by Prasanna et el majority of women (74\%) in their study group belonged to the age group of 21-30 years. ${ }^{14}$

\section{Clinical features}

In current study, most common presenting feature was Pain in abdomen $(80.9 \%)$, followed by bleeding PV $(60 \%)$, amenorrhoea $(60 \%)$ and nausea and vomiting $(32.9 \%)$. Kumari et al and Shetty et al reported pain in abdomen in $88.2 \%$ and amenorrhoea in $70.5 \%$ cases. $^{8,15}$ Kumari et al and Gaddagi and Chandrashekhar et al reported adnexal mass in $64.7 \%$ and $70.3 \%$ cases respectively. ${ }^{11,15}$ Swami et al, reported pain in abdomen was present in all 34 cases, followed by amenorrhea which was present in $97.05 \%$ cases and bleeding $\mathrm{P} / \mathrm{V}$ in $76.47 \%$ cases. ${ }^{16}$ Chhate et al, reported abdominal pain and amenorrhea was present in $92.47 \%$ and $77.41 \%$ cases suggestive of most common presentation of patient with ectopic pregnancy. ${ }^{17}$ Prasanna et al reported $96 \%$ of the patients had history of amenorrhea, $90 \%$ had history of pain abdomen and $68 \%$ had bleeding PV. ${ }^{14}$

\section{Parity}

In current study, we reported nulliparous in $31.5 \%$ followed by second para (30.1\%), primi para (27.4\%) and third para $(11 \%)$. Swami et al, reported incidence of ectopic pregnancy in Multigravida is $64.71 \%$ and that of primigravida is $35.29 \% .{ }^{16}$ The incidence in multigravida is high as they are more exposed to post abortal, 
puerperal infections and STD's. ${ }^{16}$ In study done by Prasanna et al majority of women with ectopic pregnancy were multigravidae (84\%). ${ }^{14}$ Current study reported $52 \%$ EP reported in less than 5 years of active married life $(52.1 \%)$, followed by 5 years to 10 years $(34.2 \%)$ and more than 10 years $(13.7 \%)$. We reported average active married life $6.3 \pm 4$ years. Present study reported regular menses in $86.3 \%$ patients and irregular menses in $13.7 \%$ patients. While Kharat et al reported primigravida in $17.5 \%$ whereas multiparas were $82.5 \% .^{18}$

\section{Risk factors}

Present study reported history of previous abortion (30\%) and pelvic inflammatory disease $(30 \%)$ as most common risk factor based on past history. We also reported history of infertility in $13.7 \%$ patients, use of IUCD in $11 \%$, tubal ligation in $8.3 \%$ and prior history of ectopic pregnancy in $1.4 \%$ patients. Similar findings reported in study conducted by Kumari et al reported pelvic inflammatory disease as strongest risk factor in $35.29 \%$ while similar result reported by Yakasai et al. $31.68 \%$ incidence. ${ }^{15,19}$ Kumari et al and Singh et al reported history of tubal ligation in $23 \%$ of patients. ${ }^{15,20}$ Kumari et al reported IUCD with EP in $11.76 \%$ of patients. ${ }^{15}$

\section{General examination}

Our study reported tenderness in $45.2 \%$, pallor in $38.4 \%$, abdominal distension in $37 \%$, tachycardia in $27.4 \%$, guarding in $23.3 \%$ and raise temperature in $19.2 \%$. our study reported retroverted and normal uterus in $65.6 \%$ was, bulky uterus in $17.8 \%$ and ante everted and normal in $16.4 \%$. We found fornices tender in $93.2 \%$ patients, fullness in $30.1 \%$ patients and mass in $23.3 \%$ patients. Swami et el reported $82.35 \%$ presented with adnexal mass, $79.41 \%$ with cervical motion tenderness, $76.47 \%$ had bleeding $\mathrm{p} / \mathrm{v}, 50 \%$ with pallor, $32.35 \%$ with abdominal lump and tenderness and $11.76 \%$ with fullness in pouch of douglas. ${ }^{16}$

\section{Diagnostic tests}

Study conducted by Kumari et al did UPT in all patients and ultrasound was done in $15(88.23 \%)$ patients for the diagnosis. ${ }^{15}$ UPT was positive in $14(82.35 \%)$ patients. ${ }^{14}$ While in our study UPT was done and found positive in $100 \%$ of cases. Study conducted by Shraddha Shetty K et.al reported UPT positivity in $87.1 \% .^{8} \mathrm{We}$ reported average hemoglobin and beta hCG $9.9 \pm 2.1 \mathrm{mg} / \mathrm{dl}$ and $3886 \pm 3098.6$ respectively.

Present study reported unruptured EP found in $57.53 \%$, followed by ruptured EP in $38.35 \%$ and adnexal mass in $4.1 \%$ patients. Swami et al reported out of 33 tubal pregnancy tubal rupture was seen in 27 cases $(79.41 \%)$, tubal abortion in 4 cases $(11.76 \%)$ and unruptured tubal pregnancy in $(05.88 \%)$ cases. Contrary to our study, tubal rupture is the most common fate of tubal pregnancy in their study. ${ }^{16}$

\section{Site of pregnancy}

In current study, we found most common site of ectopic pregnancy was ampullary in $31.5 \%$ patients, followed by infundibulum in $26 \%$ patients, isthmus in $21.9 \%$ patients, site not known in $19.2 \%$ patients and interstitial in $1.3 \%$ patients. This shows that ampullary region is the most common location for tubal ectopic gestation. Chate et al, reported commonest site for ectopic pregnancy is ampulla in present study accounting for $51.61 \%$ cases followed by fimbria in $19.35 \%$ cases. Isthmus was next most common site in $10.76 \%$ cases. Ovary and corneal involvement was seen in $9.67 \%$ and $8.61 \%{ }^{18}$ Unfortunately, during the study period, we did not encounter any other site ectopics, only tubal ones. Present study reported involvement of right side in $58.9 \%$ patients followed by involvement of left side in $41.1 \%$ patients. Kharat et al, reported right sided tubal pregnancy was present in $53.1 \%$ cases and left tubal involvement in $46.9 \%$ cases. $^{18}$

\section{Management}

In our treatment, most common mode of treatment was right salpingectomy in $43.8 \%$, followed by left salpingectomy in $28.8 \%$, methotrexate in $15.1 \%$, left salpingo-ophorectomy in 5.5\%, right salpingoopherectomy in $5.5 \%$ and removal of tubal abortion in $1.3 \%$ patients. Swami et el reported 30 cases $(88.24 \%)$ underwent unilateral salphingectomy. 2 (5.88\%) cases were treated with methotrexate $1 \mathrm{mg} / \mathrm{kg}$ of body weight and in $2(5.88 \%)$ cases milking was performed with postoperative methotrexate therapy. ${ }^{16}$ Study conducted by Chate et al unilateral salpingectomy was done in $75.26 \%$ cases followed by unilateral salpingooopherectomy in $21.51 \%$ cases. Laparoscopic salpingectomy was done in $2.15 \%$ cases. Salpingostomy was done in $1.08 \%$ cases. ${ }^{17}$ Present study reported most common mode of surgery being laparoscopy in $64.4 \%$ patients, followed by laparotomy in $20.5 \%$ patients and no surgical intervention in $15.1 \%$ patients. In our study, blood transfusion needed in $32.9 \%$ patients and blood transfusion was not required in $67.1 \%$ patients. $58.88 \%$ of patients recovered with 2 units of blood transfusion. 2 cases required 4 units of blood transfusion.

Limitations of this study was small sample size. Hospital based study, difficult to generalize the findings, distance travelled was not evaluated. This could have helped policy makers.

\section{CONCLUSION}

In nutshell, this paper concluded that Ectopic pregnancy a cataclysm as well as a hindrance to reproductive performance, should be considered a public health issue. Overall, our results demonstrate with strong effect that with timely and efficient care, prognosis is favourable even in severe shock conditions. Therefore, it's suggested that by providing adequate materials, equipments and man-power at referring health care facilities combined 
with good access roads and efficient transportation; at time presentation and swift management of patients can be ensured.

\section{Funding: No funding sources}

Conflict of interest: None declared

Ethical approval: Not required

\section{REFERENCES}

1. Ectopic pregnancy in Conakry, Guinea. Bull World Health Organ. 2002;80:365-70.

2. Ectopic Pregnancy. National Health Portal India. April, 2017. Available at: https://www.nhp.gov.in/disease/gynaecology-andobstetrics/ectopic-pregnancy.

3. Jeffcoate's principles of Gynaecology. Narendra Malhotra Pratap Kumar. Seventh international edition. New Delhi: Jitendar P Vij, Jaypee Brothers Medical Publishers (P) Ltd.; 2008.

4. Arup KM, Niloptal, Kakali SK, Pradip. Ectopic pregnancy an analysis of 180 cases. J Indian Med Assoc. 2007;105:308-14.

5. Shaw JT, Dry SK, Critchley Ho, Horne AW. Current knowledge of the aetiology of human tubal ectopic pregnancy. Human Report Update. 2010;16:32-44.

6. Udgiwe GO, Umeonihu OS, Mbuchu. Ectopic pregnancy: a 5-year review of cases at Nnamdi Azikiwe University Teaching Hospital (NAUTH) Nnewi. Niger Med. 2010;51:160-3.

7. Wakankar R, Kedar K. Ectopic pregnancy-rising trend at Indira Gandhi Government Medical College, Nagpur. Int J Sci Stud. 2015;3(5):18-22.

8. Shraddha Shetty K, Anil Shetty K. A clinical Study of Ectopic pregnancies in a tertiary care hospital of Mangalore, India: Inn J Med Health Sci. 2014;4(1):305-9.

9. Murugesan A, Prabhu KMM. A retrospective study of ectopic pregnancies in a tertiary care hospital. Int J Reprod Contracept Obstet Gynecol. 2016;5(8):253740.

10. Costa J, Bouyer J, Ughetto S, Gerbaud L, Fernandez $\mathrm{H}$, Pouly JL, et al. Ectopic pregnancy is again on the increase. Recent trends in the incidence of ectopic pregnancies in France (1992-2002). Human Repro. 2004;19(9):2014-8.

11. Gaddagi RA, Chandrashekhar AP. A clinical study of ectopic pregnancy. JCDR. 2012;6:867-9.

12. Panchal D, Vaishnav G, Solanki K. Study of management in patient with ectopic pregnancy. NJIRM. 2011;2(3):91-4.

13. Dayal N, Srivastava A. A retrospective study on ectopic pregnancy in a tertiary care hospital. IOSR J Dent Med Sci. 2019;18(4):11-4.

14. Prasanna B, Jhansi CB, Swathi K, Shaik MV. A study on risk factors and clinical presentation of ectopic pregnancy in women attending a tertiary care centre. IAIM. 2016;3(1):90-6.

15. Kumari S, Prasad D, Sinha A, Parween S. Retrospective study of ectopic pregnancy in tertiary care centre. IAIM. 2018;5(1):95-9.

16. Swami MB, Sharma P, Tyagi M, Kuswaha R, Harit J. Clinical study of ectopic pregnancy. J Evol Med Dent Sci. 2015;4(86):15057-62.

17. Chate MT. Clinical study of ectopic pregnancy: Int J Reprod Contracept Obstet Gynecol. 2017;6(8):3498501.

18. Kharat D, Giri PG, Fonseca M. A study of epidemiology of ectopic pregnancies in a tertiary care hospital of Mumbai, India.: Int $\mathbf{J}$ Reprod Contracept Obstet Gynecol. 2017;6(9):3942-6.

19. Yakasai IA, Abdullahi J, Abubakar IS. Management of ectopic pregnancy in Aminu Kano teaching hospital Kano Nigeria: A 3 year. Glob Adv Res J Med Med Sci. 2012;1:181-5.

20. Singh S, Pukale RS. Clinical study of ectopic pregnancy in a rural setup: a two-year survey. Natl $\mathbf{J}$ Med Res. 2014;4(1):37-9.

Cite this article as: Parmar S, Sharma N, Dhakar V. Ectopic pregnancy: an observational study in a tertiary care centre of Southern Rajasthan, India. Int J Reprod Contracept Obstet Gynecol 2020;9:516-23. 